\title{
Analysis of Deflection of a Fixed Ridge Beam due to Pressure Applied on the Beam
}

\author{
D.S.Rodrigo, H.M.N.Sewwandi
}

\begin{abstract}
The roof is a major component in building and housing construction and also it is the identity of the building or house. This study is focused on kingpost and beam joinery in gable roof types that commonly used in hotel entrances, cabanas, summerhouses, greenhouses and assembly halls in temples. For this study, the simplest structure of king post which is the structure that only the kingpost connects to the horizontal beam is used and mortise and tenon joinery is used to connect beam and king posts; the kingpost is used as a mortise element and beam is used as a tenon element. Therefore the ridge beam is a fixed which is supported at both free ends and is restrained against rotation and vertical movement. The study is considered the jack wood beam which has the length 198 inches $(16.5$ feet $=$ $5.03 \mathrm{~m}), 11$ jack wood rafters that have the length 144 inches $(12$ feet) and two jack wood kingpost trusses that have kingposts with the length 44 inches (3.8 feet). Generally, carpenters in Sri Lanka use 8-11 feet as the range of standard distance between king post trusses.

In this study, an attempt will be made to investigate the deformation of a ridge beam of under pressure exerted by rafters, tiles and kingpost trusses and from that to detect the optimum distance between kingpost trusses that can be used to design the king post beam joinery more effective way. Euler-Bernoulli Beam theory and Fourier series were the mathematical tools, which was used in the study. The shape of a deflected beam can be described by the Euler-Bernoulli Differential Equation.

The results showed that the minimum deflection values have occurred at the standard range that used by carpenters. By examined those results, the optimum range for distance between kingpost trusses is 8-11 feet and when considering this range minimum deflection values have occurred around 9 - 9.5 feet. The results obtained from this study can be used to design the king post beam joinery more effective way.
\end{abstract}

Index Terms - Euler-Bernoulli Beam theory, Fixed beam, King post, Mortise and tenon joinery

\section{INTRODUCTION}

In traditional timber framing, the kingpost truss is used for the simple roof truss. Nowadays there are many different structural types of king post trusses are used. For this study, the simplest structure of kingpost which is the structure that only the kingpost connects to the horizontal beam is used. The beams are structural elements that resist loads applied laterally to their axis. They typically transfer loads imposed along their length to their endpoints where the loads are transferred to walls, columns, foundations, and so on. A joint is an area where two separate pieces connect. In timber framing, there are many different types of joints and connections.

D.S. Rodrigo, Department of Mathematics, University of Sri Jayewardenepura, Sri Lanka

H.M.N. Sewwandi, Department of Mathematics, University of Sri Jayewardenepura, Sri Lanka
Traditional joinery is the classic way to connect timbers in post $\&$ beam and timber frame structures. The king post and beam joinery is one of traditional joinery and it is an elegant and beautiful style of construction. The behavior of a deflected beam can be described by a fourth-order linear differential equation and that relationship among the deflection function and pressure function applied load on the beam clearly stated in the Euler-Bernoulli differential equation. The deflection of a beam refers to the movement of a beam from its original position due to the forces and loads being applied to the member.

\section{THEORY BACKGROUND}

\section{A. Euler-Bernoulli Beam theory}

Euler-Bernoulli Beam theory was developed around 1750 by Leonhard Euler and Daniel Bernoulli. It is a simple and effective method to calculate the behavior of beams when a load is applied therefore the Euler-Bernoulli differential equation describes the relationship between the deflection function and pressure function applied load on the beam. This is also known as engineer's beam theory or classical beam theory.

Euler-Bernoulli Differential Equation

$\frac{d^{4} y(x)}{d x^{4}}=\frac{1}{E I} q(x)$

where

$\mathrm{y}(\mathrm{x})$ - Deflection function. (m)

$\mathrm{q}(\mathrm{x})$ - Deflection pressure per unit length at point $\mathrm{x} .(\mathrm{N})$

$\mathrm{E}$ - Modulus of Elasticity of the beam. $\left(\mathrm{Nm}^{-2}\right)$

I - Moment of inertia of the beam. $\left(\mathrm{m}^{4}\right)$

The Euler-Bernoulli Beam theory relies on a couple of major assumptions. Assumptions:

- Any section of a beam is a flat plane before the deformation of the beam and it will remain after the deformation of the beam.

- The deformed beam angles are very small.

\section{B. Deflection of a fixed beam under a lateral load}

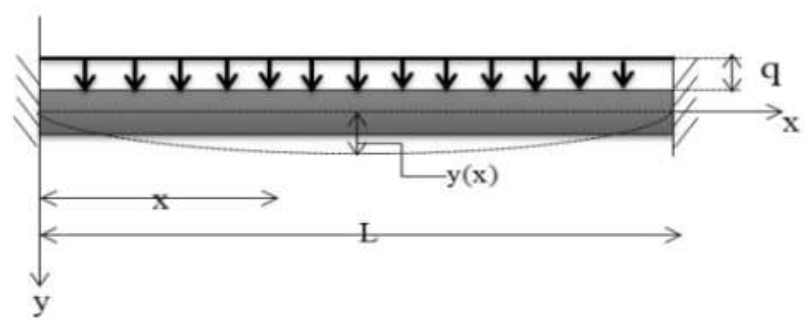

Fig. 1 
A fixed beam is supported at both free ends and is restrained against rotation and vertical movement. The following figure shows a fixed beam under a lateral load.

Taking the simplest case of the fixed beam with uniform cross-section subjected to a lateral load only, the differential equation of the deflection is

$$
\frac{d^{4} y(x)}{d x^{4}}=\frac{1}{E I} q(x)
$$

The general expression for $\mathrm{y}(\mathrm{x})$ is

$y(x)=\sum_{n=1}^{\infty} a_{n}\left\{-\left(\frac{x^{3}}{L^{3}}-\frac{2 x^{2}}{L^{2}}+\frac{x}{L}\right)-(-1)^{n}\left(\frac{x^{3}}{L^{3}}-\frac{x^{2}}{L^{2}}\right)+\frac{1}{n \pi} \sin \left(\frac{n \pi x}{L}\right)\right\} \mathrm{T}$

he first derivative for $\mathrm{y}(\mathrm{x})$ is

$$
\frac{d y(x)}{d x}=\sum_{n=1}^{\infty} a_{n}\left\{-\left(\frac{3 x^{2}}{L^{3}}-\frac{4 x}{L^{2}}+\frac{1}{L}\right)-(-1)^{n}\left(\frac{3 x^{2}}{L^{3}}-\frac{2 x}{L^{2}}\right)+\frac{1}{L} \cos \left(\frac{n \pi x}{L}\right)\right\}
$$

The boundary and initial conditions for deflection of a fixed beam can be represented as follows.

$\mathrm{y}(0)=0$ and $\mathrm{y}(\mathrm{L})=0$

$\frac{d y(0)}{d x}=0$ and $\frac{d y(L)}{d x}=0$

\section{Fourier series}

A Fourier series is an expansion of a periodic function in terms of an infinite sum of sine and cosine.

Let $f(x)$ is a periodic function with period $2 L$, the Fourier expansion of the function $\mathrm{f}(\mathrm{x})$ is written as,

$$
\begin{aligned}
& f(x)=\frac{a_{0}}{2}+\sum_{n=1}^{\infty}\left[a_{n} \cos \frac{n \pi x}{L}+b_{n} \sin \frac{n \pi x}{L}\right] \\
& a_{n}=\frac{1}{L} \int_{-L}^{L} f(x) \cos \frac{n \pi x}{L} d x \\
& b_{n}=\frac{1}{L} \int_{-L}^{L} f(x) \sin \frac{n \pi x}{L} d x
\end{aligned}
$$

\section{A. Modulus of Elasticity (MOE) of wood}

The modulus of elasticity of wood is a material property that describes wood's stiffness. In the simple terms, modulus of elasticity is the ratio of stress to the strain of a material in deflection. From the Hook's law, the modulus of elasticity is defined as the following equation.

$$
E=\frac{\sigma}{\varepsilon}
$$

where $\varepsilon=$ Strain (no unit or $\%$ ) and $\sigma=\operatorname{Stress}(\mathrm{MPa})$

The value of Modulus of Elasticity is constant and is related to the beam material. Its SI unit is the Pascal $(\mathrm{Pa})$ or $\mathrm{N} / \mathrm{m}^{2}$ and the practical units used are Mega-Pascal (MPa or $\mathrm{N} / \mathrm{mm}^{2}$ ) or Giga Pascal (GPa or $\mathrm{kN} / \mathrm{mm}^{2}$ ).

\section{E. Moment of inertia of the beam}

The moment of inertia is a term used to describe the capacity of a cross-section to resist bending. So the moment of inertia of a beam is the value determined by the beam's cross-sectional shape and thickness. For this study is considered the moment of inertia of the rectangular shape body.

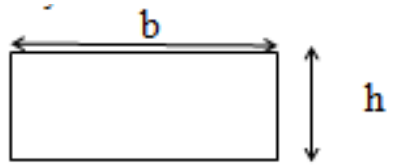

Fig. 2
Moment of inertia for rectangular shape body $(I)=\frac{b h^{3}}{12}$ where $\mathrm{h}$ is the dimension in the plane of bending.

\section{METHODOLOGY}

First, this paper focuses to obtain maximum deflection of the jack wood beam when the beam is fixedly supported by using kingpost trusses.

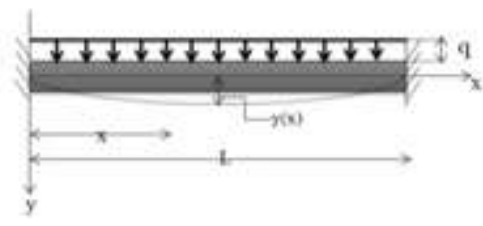

Fig. 3

Consider a fixed beam is shown in the following figure. Note the direction of the y-axis, which was chosen to make $\mathrm{y}(\mathrm{x})$ positive. It is uniformly loaded $\mathrm{q}$ per unit length. The deflection $\mathrm{y}(\mathrm{x})$ of the beam is sought. The axis of a beam deflects from its initial position under the action of applied forces. The function $\mathrm{y}(\mathrm{x})$ is satisfied by the differential equation

$$
\frac{d^{4} y(x)}{d x^{4}}=\frac{1}{E I} q(x)
$$

where $1 / \mathrm{EI}$ is the rigidity of the beam.

The general expression for $\mathrm{y}(\mathrm{x})$ which makes $\mathrm{y}$ and $\frac{d y}{d x}$ zero at both ends is

$$
y(x)=\sum_{n=1}^{\infty} a_{n}\left\{-\left(\frac{x^{3}}{L^{3}}-\frac{2 x^{2}}{L^{2}}+\frac{x}{L}\right)-(-1)^{n}\left(\frac{x^{3}}{L^{3}}-\frac{x^{2}}{L^{2}}\right)+\frac{1}{n \pi} \sin \left(\frac{n \pi x}{L}\right)\right\}
$$

Assuming the validity of the fourfold by term-by-term differentiation, obtain

$$
\frac{d^{4} y}{d x^{4}}=\sum_{n=1}^{\infty} a_{n}\left(\frac{n^{3} \pi^{3}}{L^{4}}\right) \sin \left(\frac{n \pi x}{L}\right)
$$

Then expand $\mathrm{q}(\mathrm{x})=\mathrm{q}$ into the Fourier sine series

$$
q(x)=q=\sum_{n=1}^{\infty} q_{n} \sin \left(\frac{n \pi x}{L}\right)
$$

Where $q_{n}=\frac{2}{L} \int_{0}^{L} q \sin \left(\frac{n \pi x}{L}\right) d x \quad \mathrm{n}=1,2,3 \ldots$

$$
\begin{array}{r}
q_{n}=\frac{2}{L} \int_{0}^{L} q \sin \left(\frac{n \pi x}{L}\right) d x=-\frac{2 q}{L}\left[\frac{\cos \frac{n \pi x}{L}}{\frac{n \pi}{L}}\right] \\
=\frac{-2 q}{n \pi}[1-\cos (n \pi)]
\end{array}
$$

$q_{n}= \begin{cases}\frac{4 q}{n \pi} & \text { when } n \text { is odd } \\ 0 & \text { when } n \text { is even }\end{cases}$

By (1), (2) and (3)

$\sum_{n=1}^{\infty} a_{n}\left(\frac{n^{3} \pi^{3}}{L^{4}}\right) \sin \left(\frac{n \pi x}{L}\right)=\frac{1}{E I} \sum_{n=1}^{\infty} q_{n} \sin \left(\frac{n \pi x}{L}\right)$

When $\mathrm{n}$ is even, $a_{n}=0$ and when $\mathrm{n}$ is odd, 


$$
\begin{aligned}
& a_{n}\left(\frac{n^{3} \pi^{3}}{L^{4}}\right)=\frac{1}{E I} \frac{4 q}{n \pi} \\
& a_{n}=\frac{4 q L^{4}}{E \operatorname{In}^{4} \pi^{4}}
\end{aligned}
$$

Hence

$y(x)=\sum_{n=1}^{\infty} a_{n}\left\{-\left(\frac{x^{3}}{L^{3}}-\frac{2 x^{2}}{L^{2}}+\frac{x}{L}\right)-(-1)^{n}\left(\frac{x^{3}}{L^{3}}-\frac{x^{2}}{L^{2}}\right)+\frac{1}{n \pi} \sin \left(\frac{n \pi x}{L}\right)\right\}$

$y(x)=\frac{4 q L^{4}}{E I \pi^{4}} \sum_{n=1,3,5, \ldots}^{\infty} \frac{1}{n^{4}}\left(\frac{x^{2}}{L^{2}}-\frac{x}{L}+\frac{1}{n \pi} \sin \left(\frac{n \pi x}{L}\right)\right)$

Then this study is considered the jack wood beam which has the length 198 inches $(16.5$ feet $=5.03 \mathrm{~m}), 11$ jack wood rafters that have the length and cross-sectional surface area respectively 144 inches (12 feet) and $2 \times 3$ inch $^{2}$ and two jack wood kingpost trusses that have kingposts with the length and cross-sectional surface area respectively 44 inches (3.8 feet) and $3 \times 5$ inch $^{2}$. The angle between beam and rafters is approximately $39.81^{\circ}$. Also in this study is viewed six beams types that have different cross-sectional area; $2 \times 4$ inch $^{2}$, $2 \times 5$ inch $^{2}, 2 \times 6$ inch $^{2}, 3 \times 4$ inch $^{2}, 3 \times 5$ inch $^{2}$ and $3 \times 6$ inch $^{2}$. In this study clay tile which has a 9-inch width, 16-inch length and $2.53 \mathrm{~kg}$ weight are used as the roof covering material. By considering following Fig. 4,

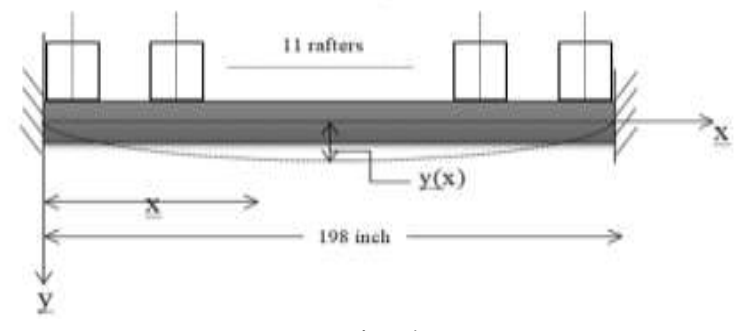

Fig. 4

$$
\begin{aligned}
& y(x)=\sum_{n=1}^{\infty} a_{n}\left\{-\left(\frac{x^{3}}{L^{3}}-\frac{2 x^{2}}{L^{2}}+\frac{x}{L}\right)-(-1)^{n}\left(\frac{x^{3}}{L^{3}}-\frac{x^{2}}{L^{2}}\right)+\frac{1}{n \pi} \sin \left(\frac{n \pi x}{L}\right)\right\} \\
& \frac{d^{4} y}{d x^{4}}=\sum_{n=1}^{\infty} a_{n}\left(\frac{n^{3} \pi^{3}}{L^{4}}\right) \sin \left(\frac{n \pi x}{L}\right) \\
& q(x)=q=\sum_{n=1}^{\infty} q_{n} \sin \left(\frac{n \pi x}{L}\right) \\
& \text { where } q_{n}=\frac{2}{L} \int_{0}^{L} q \sin \left(\frac{n \pi x}{L}\right) d x \mathrm{n}=1,2,3 \ldots
\end{aligned}
$$

Then different deflection values were obtained by changing the beams that have different cross-sectional areas. Finally, the study analyzes the optimum range for the distance between two king post trusses that can be used by using the range of minimum deflection values.

\section{EXPERIMENTAL RESULTS}

The modulus of elasticity of jack wood, the moment of inertia of the different wood beam and weight of the beam and weight of the rafters and tiles were used to calculate the deflection of the beam. Following results were obtained by changing the distance between two king post trusses under different sizes of beams. The MATLAB software is used to draw deflection curves of the beam when it is fixedly supported. The simulation results from MATLAB can be seen in the following figures.

1) Beam with cross-sectional area $2 \times 4$ inch $^{2}$

Case 01: In this situation, the distance between two king post trusses is 7.5 feet (90 inches).

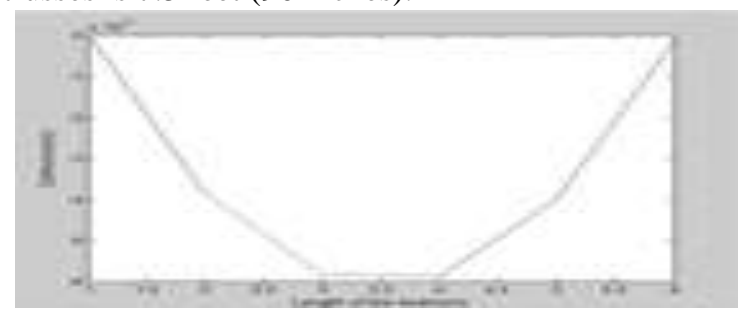

Fig. 5

Case 02: In this situation, the distance between two king post trusses is 8 feet (96 inches).

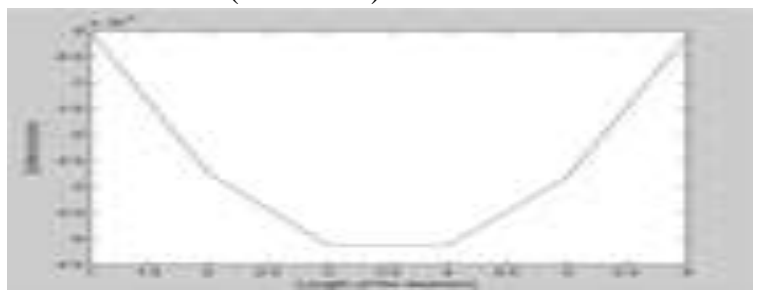

Fig. 6

Case 03: In this situation, the distance between two king post trusses is 8.5 feet (102 inches).

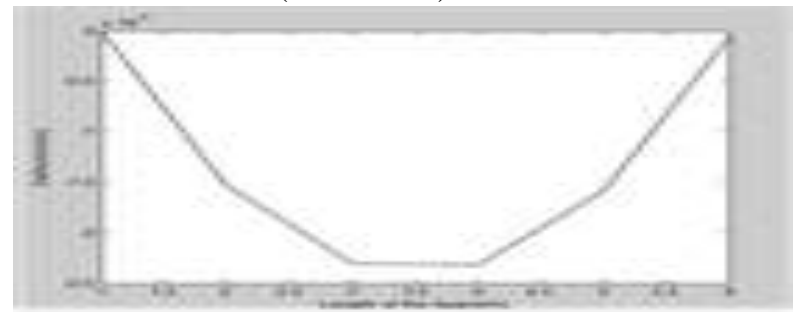

Fig. 7

Case 04: In this situation, the distance between two king post trusses is 9 feet (108 inches).

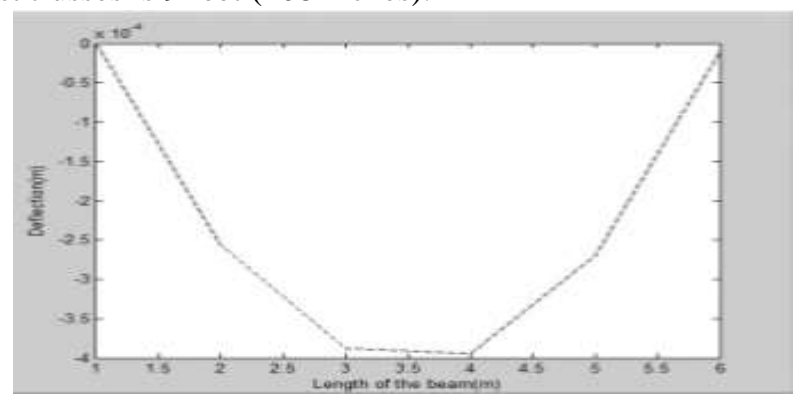

Fig. 8

Case 05: In this situation, the distance between two king post trusses is 9.5 feet (114 inches).

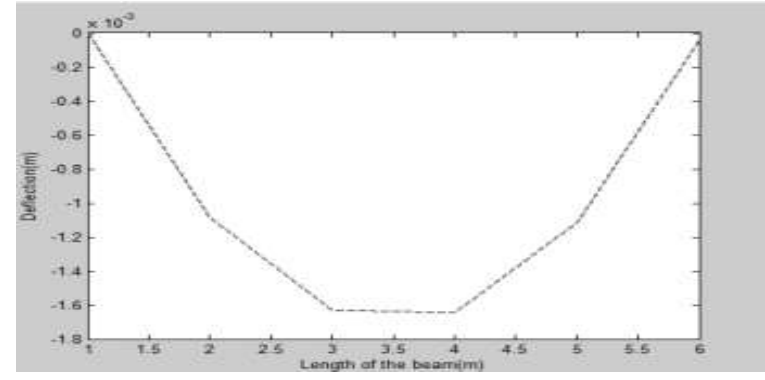

Fig. 9 
Case 06: In this situation, the distance between two king post trusses is 10 feet (120 inches).

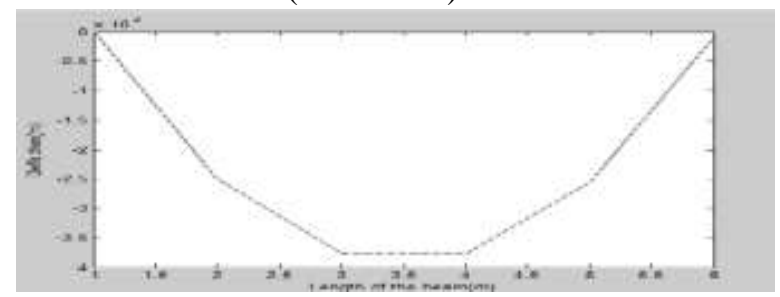

Fig. 10

Case 07: In this situation, the distance between two king post trusses is 126 inches (10.5 feet).

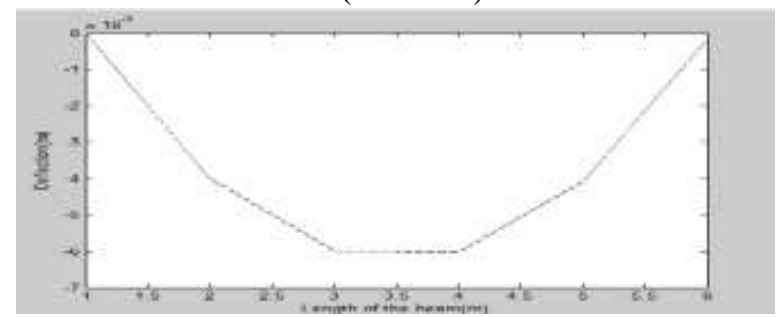

Fig. 11

Case 08: In this situation, the distance between two king post trusses is 132 inches ( 11 feet).

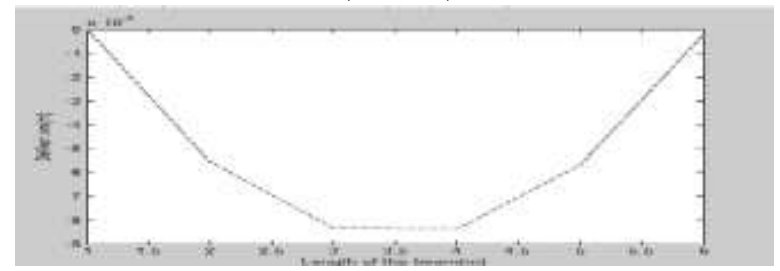

Fig. 12

Case 09: In this situation, the distance between two king post trusses is 138inches (11.5 feet).

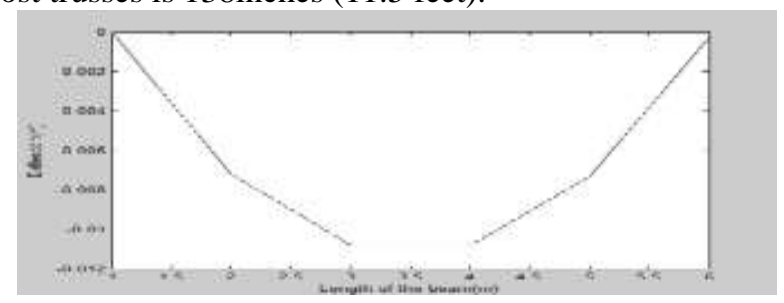

Fig. 13

By considering all graphs, following be constructed.

Table I

The maximum deflection value of each case is represented

\begin{tabular}{|c|c|}
\hline $\begin{array}{l}\text { The distance between two } \\
\text { king post trusses (feet) }\end{array}$ & $\begin{array}{c}\text { The Maximum } \\
\text { deflection }(\mathrm{m})\end{array}$ \\
\hline 7.5 & 0.0059 \\
\hline 8 & 0.0041 \\
\hline 8.5 & 0.0023 \\
\hline 9 & 0.0003942 \\
\hline 9.5 & 0.0016 \\
\hline 10 & 0.0038 \\
\hline 10.5 & 0.0060 \\
\hline 11 & 0.0084 \\
\hline 11.5 & 0.0108 \\
\hline
\end{tabular}

by the following graph.

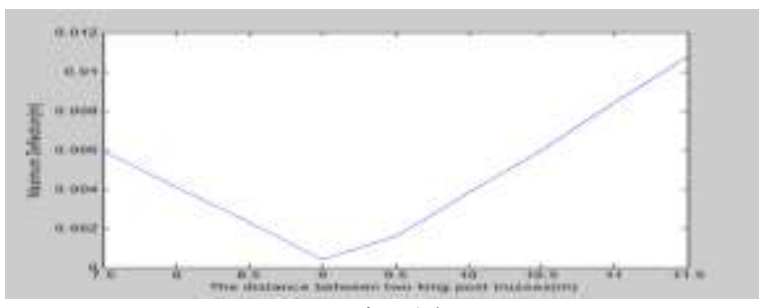

Fig. 14

According to above graph, the minimum deflection value $0.0003942 \mathrm{~m}$ is obtained when the distance between two king post trusses is 9 feet and the optimum range for the distance between two king post trusses is $8-10$ feet

The graph of deflection function for above nine cases can be obtained by using different beam sizes. From that maximum deflection value for each case can be represented by using following graphs

2) Beam with cross-sectional area $2 \times 5$ inch

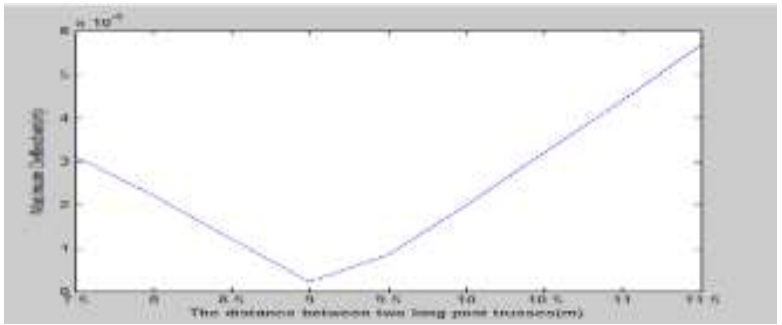

Fig. 15

According to above graph, the minimum deflection value $0.0002231 \mathrm{~m}$ is obtained when the distance between two king post trusses is 9 feet and the optimum range for the distance between two king post trusses is $8-10$ feet.

3) Beam with cross-sectional area $2 \times 6$ inch $^{2}$

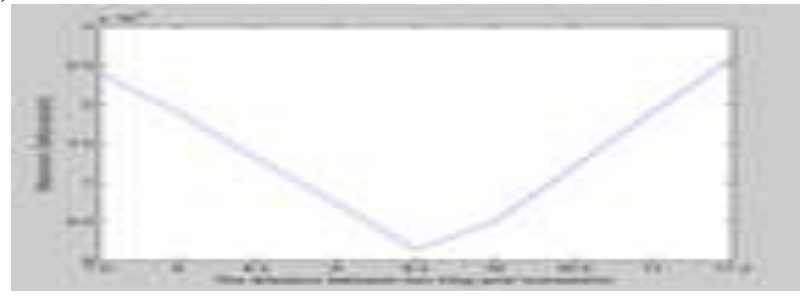

Fig. 16

According to above graph, the minimum deflection value $0.0001325 \mathrm{~m}$ is obtained when the distance between two king post trusses is 9.5 feet and the optimum range for the distance between two king post trusses is 8 - 11 feet.

4) Beam with cross-sectional area $3 \times 4$ inch $^{2}$

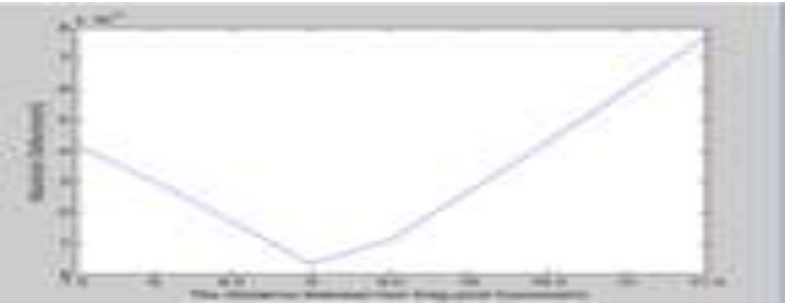

Fig. 17

According to above graph, the minimum deflection value $0.000318 \mathrm{~m}$ is obtained when the distance between two king post trusses is 9 feet and the optimum range for the distance between two king post trusses is 8- 10 feet. 
5) Beam with cross-sectional area $3 \times 5$ inch $^{2}$

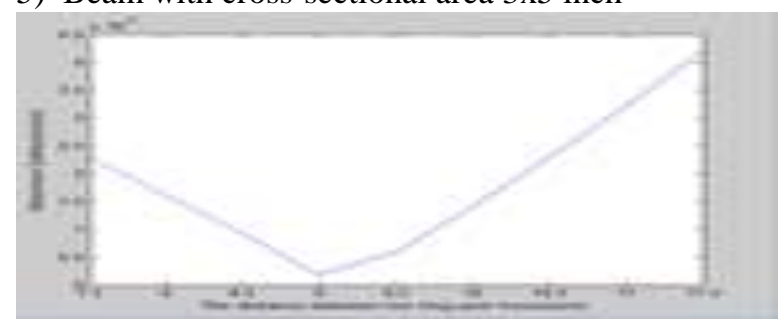

Fig. 18

According to above graph, the minimum deflection value $0.0001841 \mathrm{~m}$ is obtained when the distance between two king post trusses is 9 feet and the optimum range for the distance between two king post trusses is 8 - 10 feet.

6) Beam with cross-sectional area $3 \times 6$ inch $^{2}$

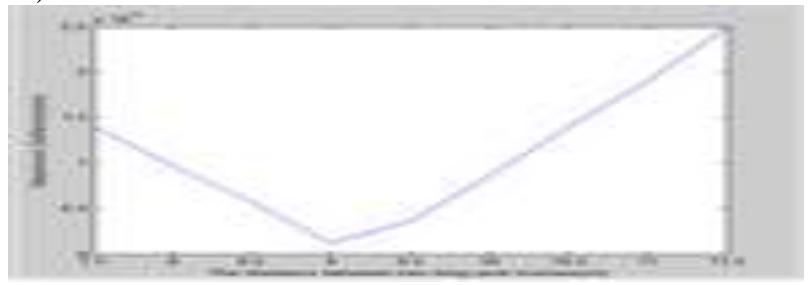

Fig. 19

According to above graph, the minimum deflection value $0.0001187 \mathrm{~m}$ is obtained when the distance between two king post trusses is 9 feet and the optimum range for the distance between two king post trusses is 8- 10 feet.

By considering all graphs, following table can be constructed.

Table II

\begin{tabular}{|c|c|c|c|}
\hline $\begin{array}{c}\text { The } \\
\text { cross-sectional } \\
\text { area of the beam } \\
\text { (inch }^{2} \text { ) }\end{array}$ & $\begin{array}{c}\text { Minimum } \\
\text { deflection } \\
\text { (m) }\end{array}$ & $\begin{array}{c}\text { The distance } \\
\text { between two } \\
\text { king post } \\
\text { trusses (feet) }\end{array}$ & $\begin{array}{c}\text { The } \\
\text { optimum } \\
\text { range for } \\
\text { the distance } \\
\text { between } \\
\text { two king } \\
\text { post trusses } \\
\text { (feet) }\end{array}$ \\
\hline $2 \times 4$ & 0.0003942 & 9 & $8-10$ \\
\hline $2 \times 5$ & 0.0002231 & 9 & $8-10$ \\
\hline $2 \times 6$ & 0.0001325 & 9.5 & $8-11$ \\
\hline $3 \times 4$ & 0.000318 & 9 & $8-10$ \\
\hline $3 \times 5$ & 0.0001841 & 9 & $8-10$ \\
\hline $3 \times 6$ & 0.0001187 & 9 & $8-10$ \\
\hline
\end{tabular}

According to above table, the minimum deflection values have occurred when the distance between two king post trusses is around from 9 to 9.5 feet and the minimum deflection value is $0.0001325 \mathrm{~m}$ and it is created when the distance between two king post trusses 9.5 feet with the beam size is that have cross-sectional area $2 \times 6$ inch $^{2}$.Also above results are showed the optimum range for the distance between two king post trusses is around from 8 to 11 feet.

\section{CONCLUSION}

Based on above results, the minimum deflection value has occurred when the distance between two king post trusses is 9.5 feet with the beam size that has cross-sectional area $2 \times 6$ inch $^{2}$.When considering all the optimum ranges, the study is concluded the common standard range which is that used by carpenters (8-11 feet) is the optimum range that has low deflection values. Therefore the study shows the importance of the standard range that used by carpenters when designing king post trusses. The study can be extended by based on beam with different materials, different roof loads, and different sizes of the buildings.

\section{REFERENCES}

[1] R. Bhatia, Fourier Series, The Mathematical Association of America United States of America, 2005.

[2] W.D.S.M Costa, and A.L.M. Mauroof,. (2005). Properties of flat clay tiles in Sri Lanka, Institution of Engineers, Sri Lanka,. Available: http://139.162.44104/bitstream/123456789/1348/1/T0773/pdf

[3] H. Rohana, I. Azmi and A. Zakiah (2010), Performance of Mortise and Tenon Connection Fastened with Wood and Steel Dowel, viewed 02 February 2018.

[4] B.F. Ruffner, The Use of Fourier Series in the Solution of Beam Problem, Oregon State Engineering Experiment Station, Oregon, 1944.

[5] T. Sakai, Solution of Problems of Applied Mechanics by Fourier Transformation Method, viewed 29 January 2018. Available: https://eprints.lib.hokudai.ac.jp/dspace/bitstream/2115/37771/1/9(2) 133-190.pdf.

[6] http://support.sbcindustry.com/Archive/2010/june/Paper 375.pdf

[7] D.A.Thatrigoda and D.S. Rodrigo. (2014). Numerical Implementation of Fourier Transforms and Associated Problems, International Journal of Multidisciplinary Studies, vol.1, Available: http://journals.sjp.ac.lk/index.php/ijms/article 